\title{
Enhanced Endothelial Cell Proliferation in Acute Kawasaki Disease (Muco-Cutaneous Lymph Node Syndrome)
}

\author{
YOSHIMI HASHIMOTO, SADAYOSHI YOSHINOYA, TAKASHI AIKAWA, \\ TADAYUKI MITAMURA, YUJI MIYOSHI, MASAHARU MURANAKA, TERUMASA MIYAMOTO, \\ YOSHIO YANASE, AND TOMISAKU KAWASAKI \\ Department of Internal Medicine and Physical Therapy, University of Tokyo School of Medicine, Tokyo, Japan \\ and Department of Pediatrics, Japan Red Cross Medical Center, Tokyo, Japan
}

\begin{abstract}
Paired sera from 30 patients with mucocutaneous lymph node syndrome (Kawasaki disease) were studied for possible effects on human vascular endothelial cells growth in vitro. The majority of sera from acute phase muco-cutaneous lymph node syndrome patients significantly enhanced endothelial cell proliferation more than those from convalescent phase patients, infectious diseases patients, and age-matched normal controls. This stimulation was considered to be specific for EC since mucocutaneous lymph node syndrome sera did not enhance fibroblast growth more than normal sera. Fractionation of the serum with gel filtration failed to clearly detect the molecular properties of this effect, although both heavy and light material possessed this activity. Extensive search for circulating immune complex in muco-cutaneous lymph node syndrome sera were negative, suggesting that the enhanced endothelial cell proliferation was due to serum components other than immune complexes. (Pediatr Res 20:943-946, 1986)
\end{abstract}

\section{Abbreviations}

MCLS, muco-cutaneous lymph node syndrome EC, endothelial cells

PBS, phosphate-buffered saline

FCS, fetal calf serum

BSA-PBSE, bovine serum albumin in PBS with EDTA

GVB, gelatin veronal buffer

PI, proliferation index

NHS, normal human serum

Kawasaki disease (MCLS) is an acute febrile disease of infants first reported in Japan in 1967 (1). Since then, many studies have described the clinical manifestations of this disease, and it is now accepted that MCLS is a systemic vasculitis associated with coronary artery involvement which occasionally leads to death fatality (2). Pathological studies of fatal MCLS cases revealed the presence of systemic vasculitis/arteritis, predominately in the coronary arteries (3-5). The etiology of MCLS is unknown. In the present study we have demonstrated the presence of a stimulating effect of MCLS sera on EC growth/proliferation in

Received October 4, 1985; accepted May 14, 1986.

Correspondence Dr. Yoshimi Hashimoto, Department of Internal Medicine and Physical Therapy, University of Tokyo School of Medicine, 7-3-1 Hongo, Bunkyoku, Tokyo, Japan.

This work was supported by the grant from the Study group of the Japanese Ministries of Welfare and Education and also by the Manabe Medical Foundation. vitro, which may contribute to the vascular damage from the disease. The possible role of circulating immune complexes was also investigated.

\section{MATERIALS AND METHODS}

Patients. Thirty MCLS patients hospitalized in Japan Red Cross Medical Center between August 1980 and July 1982 were studied. The mean age of the 30 patients $(23$ male and seven female) was $2.95 \pm 2.29$ years, ranging from 3 months to $9 \mathrm{yr}$. Twenty-three patients were treated with oral aspirin $(50 \mathrm{mg} / \mathrm{kg} /$ day), which was maintained through the convalescent period. Three patients were treated with flurbiprofen $(94 \mathrm{mg} / \mathrm{kg} / \mathrm{day})$, two patients with a combination of prednisone $(2 \mathrm{mg} / \mathrm{kg} /$ day $)$ and dypiridamole $(5 \mathrm{mg} / \mathrm{kg} /$ day $)$, one patient with a combination of prednisone and aspirin, and one patient with high dose of methylprednisone after a dose of aspirin. Age- and sex-matched normal healthy children were used as controls. Fourteen hospitalized children with common infectious diseases (acute bronchitis, sepsis, and general infection with nephritis) were also used as disease controls. Sera were obtained at different clinical stages from 30 MCLS patients.

The first serum sample was drawn on an average of the 7th disease day when all patients had fever, skin rash, oropharyngeal inflammation, and characteristic skin changes. The second serum was drawn between the 25 th and the 35 th day when most patients no longer had acute symptoms; three patients had coronary aneurysms. All the blood samples were clotted at room temperature for $2 \mathrm{~h}$, centrifuged, and stored at $-20^{\circ} \mathrm{C}$ until studied.

Gel filtration. One ml serum was applied to Sephadex G-200 column $(2.6 \times 85 \mathrm{~cm})$ equilibrated in PBS. Both normal control sera and patients' sera were fractionated with the same column. The serum fractions $(6.2 \mathrm{ml} / \mathrm{each}$ tube) were concentrated using polyethylene glycol $(40,000)$ up to original volume $(1.0 \mathrm{ml})$ and stored at $-20^{\circ} \mathrm{C}$ until assaying.

$E C$. A slight modification of the technique of Jaffe et al. (6) was used for culturing human endothelial cells. Human umbilical cords were obtained soon after normal delivery and kept in cold Dulbecco's PBS without $\mathrm{Ca}^{++}$and $\mathrm{Mg}^{++}$. The lumen of the umbilical vein was washed extensively with PBS and finally was filled with $10-12 \mathrm{ml}$ of $0.2 \%$ collagenase (Worshington BioChemical Corp., Freehold, NJ) in PBS clamped shut, and incubated at room temperature for $15 \mathrm{~min}$. The collagenase solution was then flushed from the cord and washed twice with PBS. All the effluent was collected, and the cells were washed twice with RPMI-1640 medium and suspended in culture medium. The culture medium consisted of RPMI-1640 supplemented with $25 \%$ FCS, penicillin $(200 \mu \mathrm{g} / \mathrm{ml})$, streptomycin $(100 \mu \mathrm{g} / \mathrm{ml})$, fungisone $(0.25 \mu \mathrm{g} / \mathrm{ml})$, and L-glutamine $(2 \mathrm{mM})$ (Grand Island 
Biological Co., Grand Island, NY). EC were thus grown on the plastic surface of the culture flask (Corning cat. no. 25100).

All endothelial cells used in this study were identified by detecting factor VIII antigen with indirect immunofluorescence technique as described previously $(7,8)$. Smooth muscle cells and fibroblasts, possible contaminating cell types, have different morphological characteristics from EC and contamination of monocytes was easily eliminated by extensively washing the intact lumen of the umbilical vein.

Fibroblasts. Human skin fibroblasts were primarily obtained from the forearm of a normal donor and cultured in RPMI1640 , containing $10 \%$ FCS, penicillin, and streptomycin. After $2-3$ wk at $37^{\circ} \mathrm{C}$ with $5 \% \mathrm{CO}_{2}$, the cell layer was detached with $0.1 \%$ trypsin and $0.02 \%$ EDTA, and transferred to $25 \mathrm{~cm}^{2}$ culture flask for continuous culture.

EC proliferation assay. This was done using second to third passaged cells according to the method of Kahaleh et al. (9). Ten thousand viable endothelial cells in RPMI-1640 medium with $2 \%$ FCS were seeded in triplicate wells of Falcon flat bottom microtest plates and left overnight. The medium was then replaced with RPMI medium supplemented with $20 \%$ test serum or test drug. After $48 \mathrm{~h}$ incubation, ${ }^{3} \mathrm{H}-\mathrm{TdR}$ was introduced at 1 $\mu \mathrm{Ci} / \mathrm{ml}$ concentration. Twenty-four hours laters, the medium was replaced with $0.05 \%$ trypsin- $0.01 \%$ EDTA in PBS. Then the cells were harvested on glass-fiber filters and counted in a scintillation counter. The same assay was performed using skin fibroblasts.

Immune complex assays. Three radioimmunoassays to detect immune complexes were performed as previously described (1013). Briefly, the Clq-solid phase (Clq-SP) and the monoclonal rheumatoid factor-solid phase (mRF-SP) assays were performed by coating polystylene tubes with $0.5 \mathrm{ml}$ isolated Clq $(5 \mu \mathrm{g} / \mathrm{ml})$ or $\mathrm{mRF}(85 \mu \mathrm{g} / \mathrm{ml})$ for $16 \mathrm{~h}$ at $4^{\circ} \mathrm{C}$. Remaining binding sites were blocked with $1 \%$ of bovine serum albumin in PBS containing $10 \mathrm{mM}$ EDTA $(5 \mathrm{mM}$ sodium phosphate, $0.15 \mathrm{M}$ sodium chloride, $10 \mathrm{mM}$ EDTA, pH 8.0) (BSA-PBSE). Test samples $(0.005 \mathrm{ml})$ were added to the coated tubes and BSA-PBSE $(0.495$ $\mathrm{ml}$ ) was added to bring the final volume up to $0.5 \mathrm{ml}$. After incubation for $16 \mathrm{~h}$ at $4^{\circ} \mathrm{C}$, the tubes were washed three times with $2 \mathrm{ml}$ of PBSE, and immune complexes bound to $\mathrm{Clq}$ or mRF were measured using a specific $I^{125}-F\left(a b^{\prime}\right)^{2}$ rabbit antihuman Fab. The results of both solid phase assays were recorded as ng of $F\left(a b^{\prime}\right)^{2}$ rabbit antihuman Fab bound per tube. The sensitivity and specificity of each of these assays were identical to previous reports $(11-13)$.

The red blood cell assays were performed with a $4 \%$ suspension of normal human red blood cells (type $\mathrm{O})$ in $\mathrm{GVB}(0.1 \%$ gelatin,

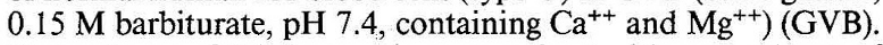
One volume of this suspension was mixed with one volume of one-fourth diluted normal human serum as a complement source and one volume of heat-inactivated test serum (non-diluted). After incubation for $15 \mathrm{~min}$ at $37^{\circ} \mathrm{C}$, the red blood cells were washed three times with GVB and resuspended in GVB at $4 \%$. Fifty $\mu \mathrm{l}$ of this suspension was incubated with $50 \mu \mathrm{l}$ of $\mathrm{I}^{125}$ antihuman IgG (Hoechst Japan Co., Tokyo, Japan) for $1 \mathrm{~h}$ at $37^{\circ} \mathrm{C}$. After washing, the cells were counted and the results were recorded as amount of heat aggregated $\mathrm{IgG}$ equivalent, as reported previously (13).

\section{RESULTS}

EC proliferation assay. We measured the ${ }^{3} \mathrm{H}$-TdR uptake of the cultured vascular EC after incubation in $20 \%$ test or control sera. We first determined EC proliferation by 18 normal sera and found no significant differences among these sera. Proliferative activity of EC, however, showed considerable variation using individual umbilical cord samples even with identical normal serum. Therefore, the results of the EC proliferation assays were expressed as an index (PI) instead of actual cpm. Six normal sera were used in one experiment and the mean cpm of

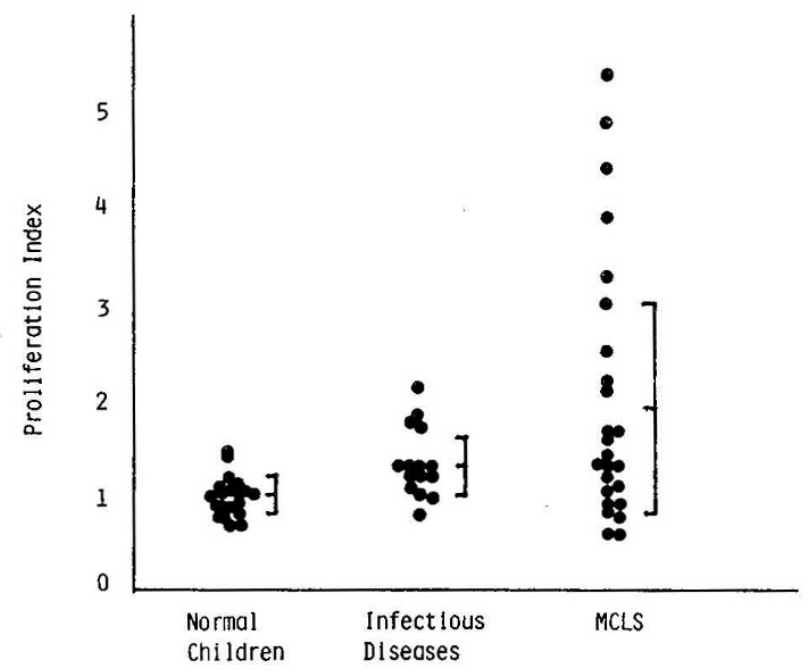

Fig. 1. The EC PI in normal children, infectious diseases, and acute MCLS. The magnitude of endothelial cell proliferation was expressed as an index which was calculated by dividing each value by the mean value of normals.

these sera were designated as 1.00 ; PI was then calculated by dividing each individual value by this mean. Figure 1 summarizes the results of the EC proliferation assay.

The proliferation indices were $1.00 \pm 0.02$ (SD) for normal children $(n=19), 1.32 \pm 0.32$ for infectious diseases patients $(n$ $=14$ ), and $1.88 \pm 1.29$ for acute phase MCLS patients. Both the indices in infectious diseases patients and MCLS patients were significantly higher than in normal children ( $p<0.001$ by MannWhitney U test). The index in MCLS patients was, furthermore, significantly higher than in infectious diseases patients $(p<$ 0.005 ).

Figure 2 shows the result of an experiment in which six paired (both first and second) sera from six MCLS patients were tested for EC proliferation activity along with sera from six normal children. The mean cpm with the first MCLS serum $(16,810 \pm$ $3,209)$ was significantly higher than those for both the second serum $(9,389 \pm 2,692)$ and the normal serum $(11,936 \pm 2,297)$ There was no difference between the second serum and the normal serum. In each case for the six MCLS patients, the first serum stimulated EC proliferation more than the second serum.

To see if this enhanced proliferation by MCLS sera was specific to EC, both EC and fibroblasts proliferation assays were done simultaneously. The result as shown in Table 1 indicates EC proliferation with MCLS sera was significantly higher than that with NHS, whereas no significant difference was observed between MCLS and NHS for the fibroblast proliferation.

In the next experiment, we fractionated the serum with Sephadex G-200 Gel filtration in an attempt to detect the molecular property of the activity observed in MCLS patients. Both the patient's and normal serum were applied to the column and each pooled fraction was concentrated to the initial serum volume and tested for EC proliferation potency. In Figure 3, cpm with each pooled fraction were plotted for both normal child serum (solid circles) and active MCLS serum (open circles). The EC donor was different in the two experiments, which explains the considerable difference of background growth. In the case of normal serum, no single fraction stimulates EC to proliferation except small peaks around both IgG and albumin fractions. In sera of active MCLS, considerable activity was observed both in the void volume and in the IgG peaks; weak activity was noted in small molecular fraction.

Immune complex assays. Since several investigators reported the presence of circulating immune complexes in MCLS sera, we further investigated the possible presence of immune complexes and its association to EC proliferation activity. Figure 4 


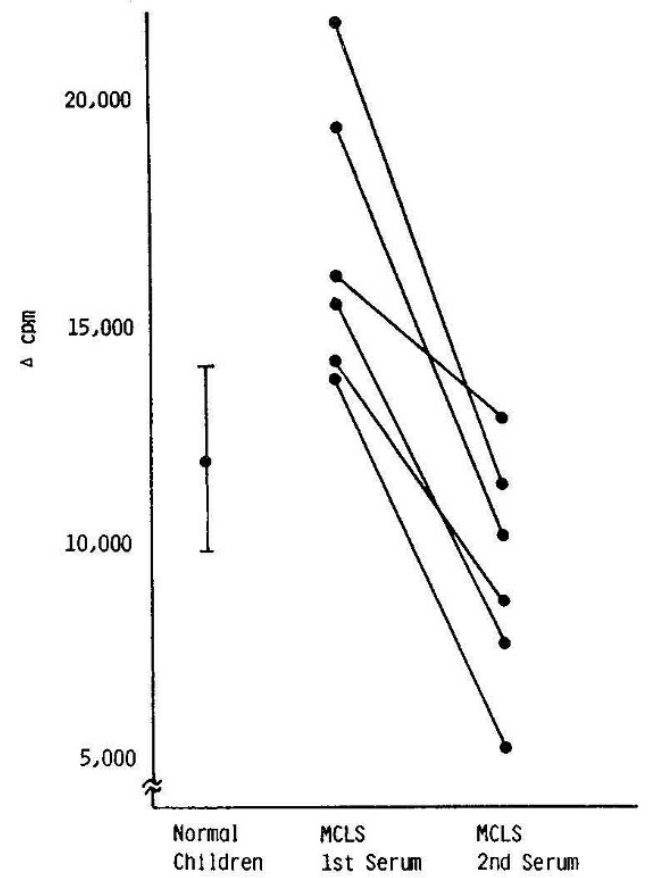

Fig. 2. The EC proliferation in MCLS. Comparison between acute and convalescent phase serum. Data are shown by actual cpm. The bar in the column for normal children indicates the range of the mean \pm 2 SD for six samples.

Table 1. Proliferation of EC and fibroblasts by MCLS sera

\begin{tabular}{lll}
\hline & \multicolumn{1}{c}{ EC } & Fibroblasts \\
\hline MCLS (8) & $7194 \pm 1821(\mathrm{SD})^{*}$ & $7323 \pm 1534$ \\
NHS (6) & $4866 \pm 510$ & $9731 \pm 1234$ \\
\hline
\end{tabular}

${ }^{*} p<0.02$.

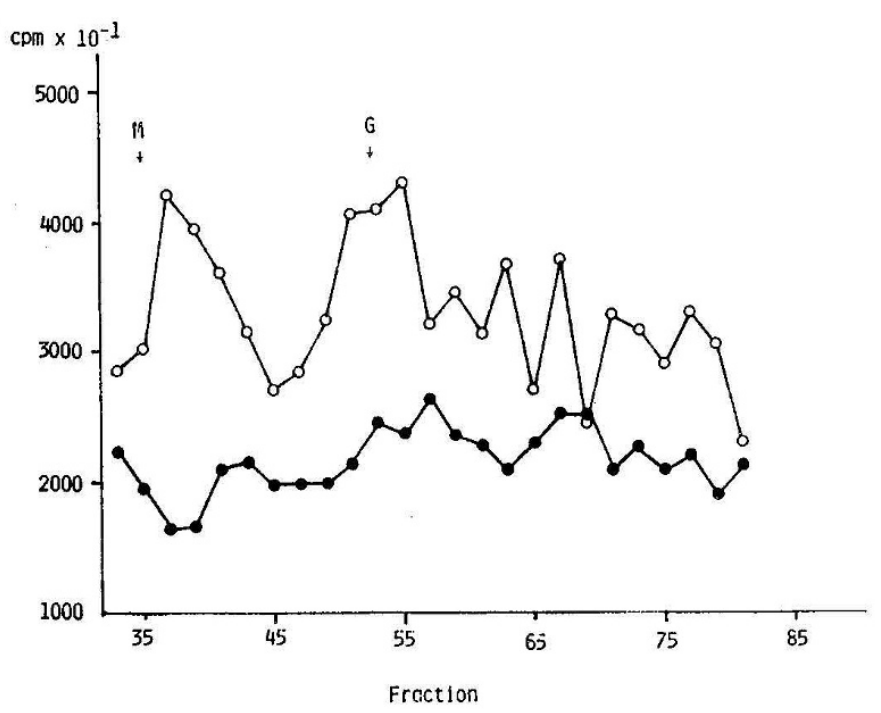

Fig. 3. EC proliferation by gel filtrated serum. Sera from a normal child (closed circles) and a patient with acute MCLS (open circles) were gel filtrated and fractionated with Sephadex G-200 column. Endothelial cell proliferation (expressed by $\mathrm{cpm}$ ) after incubation with each fraction is dotted.

depicts the distribution of the individual values for the immune complex assays obtained with the sera on the 7th day of MCLS. Results are expressed as the immune complex index obtained by dividing each patient value by the mean value of normal children

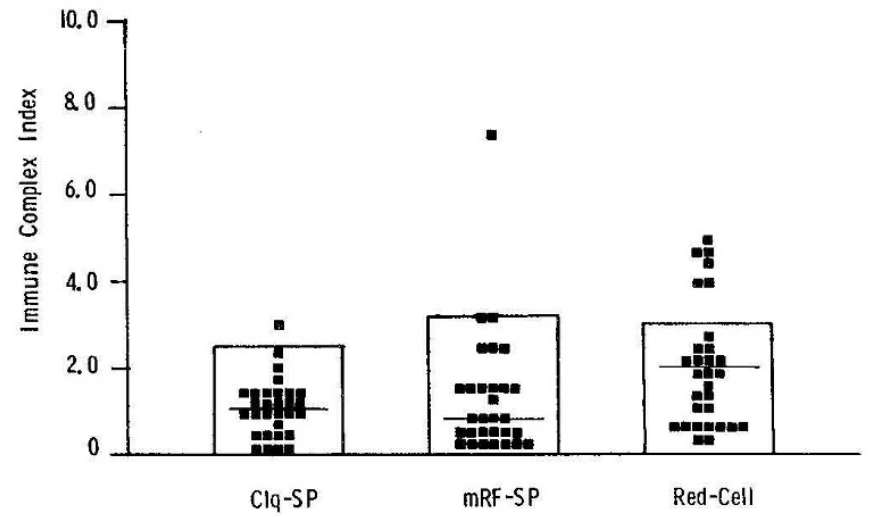

Fig. 4. Distribution of individual immune complex levels in three radioimmunoassays for MCLS patients. The squares represent the immune complex level of each patient. The boxes indicate the mean +2 $\mathrm{SD}$ of normal control in the assay.

Table 2. Effect of prednisolone and salicilate on endothelial cell proliferation

\begin{tabular}{lcc}
\hline \multicolumn{1}{c}{ Additive } & Concentration & $\mathrm{cpm}$ \\
\hline None & & 17,426 \\
Prednisolone & $0.1 \mu \mathrm{g} / \mathrm{ml}$ & 12,948 \\
& 1.0 & 12,608 \\
& 10.0 & 10,717 \\
Aspirin & 100.0 & 10,357 \\
& $1.0 \mu \mathrm{g} / \mathrm{ml}$ & 17,895 \\
& 10.0 & 17,950 \\
& 100.0 & 19,013 \\
& 1000.0 & 1,585 \\
\hline
\end{tabular}

for those assays. Abnormal values (values beyond the mean +2 SD of normal control) were observed in one patient (3.3\%) with Clq-SP, one $(3.3 \%)$ with mRF-SP, and six $(20 \%)$ with red cell assays. However, no significant difference was detected between the mean level of immune complexes of normal controls and MCLS in the three methods tested. Furthermore, no significant correlation was observed between the EC PI and the immune complex level in each patient (data not shown).

Finally, we studied the possible effect of drugs administered; prednisolone and aspirin were the main drugs. As indicated in Table 2, prednisolone suppressed EC proliferation in a dosedependent manner, whereas aspirin had little effect on EC proliferation within the concentrations tested.

\section{DISCUSSION}

In the present study, we investigated the possible effects of MCLS sera on human vascular EC proliferation in vitro. The results obtained suggest that acute phase MCLS sera have a potent activity which accelerates EC proliferation in vitro, whereas this is not present in convalescent MCLS sera or sera from normal children. This effect was considered specific for EC since acute MCLS sera did not enhance proliferation of fibroblasts. Sera from infectious diseases patients also possessed stimulatory activity but to a lesser degree than that of acute MCLS patients. This activity is probably not due to drugs administered to the patients, since these agents had no effect on EC proliferation in vitro (Table 2). An attempt to analyze this activity on column fractionation did not clearly elucidate its molecular nature, although both large molecular weight and small molecular weight substances had activity.

Circulating immune complexes have been implicated in the pathogenesis of MCLS but the results are conflicting (14-18). We, therefore, reassessed the presence of immune complexes using multiple assays simultaneously. The assay utilizing Clq 
detects complement fixing immune complexes, the mRF assay detects both complement-fixing and noncomplement fixing immune complexes (10-12), and the red cell assay detects C3bound complexes (13). Our results strongly suggest that patients with this disease do not possess significant levels of circulating immune complexes. Further, no association was observed between the EC PI and immune complex levels (data not shown). These observations indicate that circulating immune complexes do not play a major role in the enhanced EC proliferation.

"Acute phase reactants," present in the sera of infectious diseases patients may play some role. One possibility is that acute MCLS serum contains larger amount of acute phase reactants. Platelet-derived factor (19-21), endotoxin (22-23), and interleukin 1-like material (24) which are reported to stimulate EC growth may be candidates and these factors are now under investigation.

The role of the activity demonstrated in the present study on the in vivo vascular damage observed in MCLS is not yet known. Panarteritis followed by aneurysm formation is the hallmark of vascular involvement of MCLS. Endothelial cells are reported to produce both prostacyclin (25) and platelet-activating factor (26) which may modify inflammatory process via platelet function. Stimulation of EC may enhance the production of plateletactivating factor (26), which amplifies the acute inflammatory process and thrombogenesis.

Acknowledgments. The authors thank Miss Fumiko Ishizaki, Tomoko Sato, Tomoko Hayano, and Noriko Ikubo for their excellent technical assistance and Tamami Kusubae for typing the manuscript.

\section{REFERENCES}

1. Kawasaki T, Kosaki F, Shigematsu I, Yanagawa H 1974 A new infantile febrile mucocutaneous lymphnode syndrome (MLNS) prevailing in Japan. Pediatrics 54:271-276

2. Yanagisawa M, Kobayashi N, Matsuya S 1974 Myocardial infarction due to coronary thromboarteritis, following acute febrile mucocutaneous lymph node syndrome (MLNS) in an infant. Pediatrics 54:277-28

3. Tanaka N, Sekimoto K, Naoe S 1976 Kawasaki disease: relationship with infantile periarteritis nodosa. Arch Pathol Lab Med 100:81-86

4. Landing BH, Larson EJ 1977 Are infantile periarterities nodosa with coronary artery involvement and fetal mucocutaneous lymph node syndrome the same? Comparison of 20 patients from North America with patients from Hawaii and Japan. Pediatrics 59:651-662
5. Masuda H, Naoe S, Tanaka N 1981 Pathological study of coronary arteries in Kawasaki disease (MCLS). J Jap Coll Angiol 21:899-912

6. Jaffe EA, Nachman RL, Becker CG, Minick CR 1973 Culture of human endothelial cells derived from umbilical vein. J Clin Invest 52:2745-2756

7. Shingu M, Hashimoto Y, Johonson AR, Hurd ER 1981 The search for FC receptors on human tissues and human endothelial cells in culture. Proc Soc Exp Biol Med 167:147-155

8. Hashimoto Y, Hurd ER 1981 Human neutrophil aggregation and increased adherence to human endothelial cells induced by heat-aggregated $\operatorname{IgG}$ and immune complexes. Clin Exp Immunol 44:538-547

9. Kahaleh MB, Sherer GK, LeRoy EC 1979 Endothelial injury in scleroderma. J Exp Med 149:1326-1335

10. Yoshinoya S, Pope RM 1980 Circulating immune complex in acute rheumatic fever and their relationship to HLA-B5. J Clin Invest 65:136

11. Yoshinoya S, Cox RA, Pope RM 1980 Circulating immune complexes in coccidioidomycosis; detection and characterization. J Clin Invest 66:655663

12. Yoshinoya S, McDuffy S, Alarcon-Segovia D, Pope RM 1982 Detection and partial characterization of immune complex in patients with rheumatoid arthritis plus sjogren's syndrome alone. Clin Exp Immunol 48:339-347

13. Aikawa T, Mitamura T, Tanimoto K, Horiuchi Y 1979 Detection of circulating immune complexes by using human red blood cells. J Lab Clin Med 94:902915

14. Fossard C, Thompson RA 1977 Mucocutaneous lymph-node syndrom (Kawasaki disease): probable soluble-complex disorders. Br Med J 1:883-884

15. Weinding AM, Levinsky RJ, Marshall WC 1979 Circulating immune complexes in mucocutaneous lymphnode syndrome (Kawasaki disease). Arch Dis Child 54:241-243

16. Sawa F 1979 Detection of immune complexes in sera from MCLS patients. Acta Pediatr Jpn 83:493-498

17. Asako K 1979 Circulating immune complexes detected by the polyetylene glycol technique in immunological deseases of infants and children. Jap J Allerg 28:825-835

18. Furukawa S, Kaneda Y, Tsuda M, Ogiwara A, Asako K 1982 Kawasaki disease and immune complex mediated diseases. J Pediatr Prac 45:1351-1357

19. Busch C, Helden CH, Wasteson A, Westermark B 1977 Stimulation of endothelial cell proliferation by a factor released from human platelets. Bibl Anat 16:219-222

20. Maca RD, Fry GL, Hoak JC, Lob PT 1977 The effect of intact platelets on cultured human endothelial cells. Thromb Res 11:715-727

21. D'Amore P, Shepro D 1977 Stimulation of growth and calcium influx in cultured bovine aortic endothelial cells by platelets and vasoactive substances. J Cell Physiol 92:177-184

22. Gamor $\mathbf{E} 1971$ Increased mitotic activity in rabbit endothelium after endotoxin. Lab Invest 24:318-320

23. Evensen SA, Shepro D 1974 DNA synthesis in rat aortic endothelium; effect of bacterial endotoxin and trauma. Microvasc Res 8:90-96

24. Ooi BS, MacCarthy EP, Hsu A, Ooi YM 1983 Human mononuclear cell modulation of endothelial cell proliferation. J Lab Clin Med 102:428-433

25. Macintyre DE, Pearson JD, Gordon JL 1978 Localization and stimulation of prostacyclin production in vascular cells. Nature 271:549-551

26. Camussi G, Aglietta M, Malavas F, Tetta C, Piacebello W, Sanavio F, Bussolino F 1983 The release of platelet-activating factor from human endothelial cells in culture. J Immunol 131:2397-2403 